\title{
Preoperative nutrition therapy - novel developments
}

\author{
By Olle Ljungqvist, Jonas Nygren, Jonatan Hausel and Anders Thorell
}

\begin{abstract}
Elective surgery has until recently been performed in the overnight fasted state in order to reduce the risk of aspiration of gastric content during the induction of anaesthesia. However, in order to increase the preoperative well-being of surgical patients, most western countries have changed their routines during the last 10-15 years, allowing intake of clear fluids up to 2 hours before anaesthesia in most patients. Animal studies have demonstrated that undergoing different situations of stress in the fed state is superior to stress in the short-term fasted state. To evaluate whether this also applies to surgical patients, a series of clinical studies have been performed, in which the metabolic, subjective, and clinical outcome has been compared in patients randomised to preoperative carbohydrate loading or not. These studies include the development of a carbohydrate-rich drink, which has been tested and shown to be safe in the perioperative situation. The results from these studies, reviewed in this article, suggest that fasting is not the optimal way to prepare for surgical stress, and that preoperative carbohydrate loading could have metabolic as well as clinical benefits.
\end{abstract}

Keywords: carbohydrates, insulin resistance, preoperative fasting, surgery, well-being

\section{Introduction}

Elective surgery is performed on approximately $5 \%$ of the population in developed countries today (1). The operation is usually performed in the overnight fasted state. The routine has been "nil per os" or NPO, meaning that no intake of solids or fluids is allowed from midnight to the day of the operation. The overnight fasting routine was first suggested already in 1848 , as a result of the first reported death following general anesthesia (first anesthesia death). Later in that century, however, it was suggested that a better preparation for the patient was to allow a cup of tea or beef tea some hours before the operation (2). The idea of fasting before surgery was in fact questioned a long time ago.

In the early 1900s however, reports of complications from aspirations resulted in the strict recommendation of NPO (3). This routine prevailed throughout most of the last century. During the 1990s, however, it became evident that, although intake of solids presents a risk at anesthesia, there was no evidence to suggest that it is unsafe to allow most patients undergoing elective procedures to take specific beverages (4). The main reason for questioning the NPO rules was to improve patient subjective well-being, by reducing thirst and for caffeine drinkers

Olle Ljungqvist, MD, PhD, Jonas Nygren, MD, $\mathrm{PhD}$, Jonatan Hausel, MD, Anders Thorell, MD, $\mathrm{PhD}$, Karolinska Institutet at Huddinge University Hospital and Ersta Hospital, Centre of Gastrointestinal Disease, Stockholm, Sweden.

Correspondence: Olle Ljungqvist, Ersta Hospital, Centre of Gastrointestinal Disease, P.O. Box 4622 SE-116 91 Stockholm, Sweden. avoiding headaches from withdrawal symptoms. Norway was the first country to adopt new guidelines in 1993, and in that country a national survey was performed three years later, which showed no increase in aspirations due to the new routines (5). The routines that were recommended were intake of clear fluids up until 2 hours before premedication $(4,6)$. Several other countries followed the Norwegians, including Great Britain 1993, USA 1994, Sweden 1995 and Denmark 1996. The commonly recommended beverages water, tea, coffee or juices without fruit meat - have all shown to be safe $(4,6)$. However, from a metabolic and nutritional point of view, these beverages cannot be expected to cause any major changes in metabolism, and thus, even with the new and more liberal fasting guidelines, the patient will be operated in a metabolic state of fasting. Recent clinical studies suggest that this may not be the optimal metabolic situation before surgical stress. These findings indicate that carbohydrate feeding shortly before the operation may be a better way to prepare for elective surgery, and this is reviewed below.

\section{Underlying hypothesis}

The work to be presented has for the most part been done based on the hypothesis that the reactions to a physical stress depend in part on the metabolic state at the onset of the stress. Even a short period of fasting will change the metabolic state of the patient and thereby alter the responses. This has relevance for the NPO routine, in that the overnight fast represents an additional metabolic stress superimposed on the stress of the surgical insult per se.

The idea that even a brief fasting may have an impact on clinical outcome evolved from animal studies in severe stress. These models cannot be compared directly with modern surgical practice. However, since these studies played an important part in the development of the entire idea, it seems relevant to summarize them as a background. Also, there are still very little clinical data available on the effects of preoperative carbohydrates instead of overnight fasting. Therefore, we have taken the liberty of commenting on some preliminary data, which have only been presented as abstracts at international meeting.

\section{Animal studies: \\ Brief fasting - stress}

Studies in rodents subjected to hemorrhage were among the first to reveal that even a brief fast before a given insult altered the responses to the stress. In fact, Munro showed already in 1946 that a fed rat lost more nitrogen than the $24 \mathrm{~h}$ fasted animal when subjected to burn injury (7). This early observation indicated that even a brief period of fasting may affect the metabolic response to severe stress. Later Järhult et al. showed that the fasted cat developed lower blood glucose levels in response to hemorrhage compared to a fed cat and suggested an osmotic role for hyperglycemia in hemorrhage (8). This was the first indication that even a brief fast may be disadvantageous if stress is superimposed.

Our group performed a series of studies 
Table 1. Differences in a series of experiments where reactions to standardized hemorrhage or standardized endotoxin challenge were investigated in rats fed up until the start of experiments (Fed) or subjected to a $24 \mathrm{~h}$ fast (24h Fasted). Mean values, per cent or real numbers are given. $P$ values represent differences between groups.

\begin{tabular}{|c|c|c|c|c|}
\hline Parameter/Pretreatment before stress & Fed & 24h Fasted & $\mathrm{p}$-value & Ref \\
\hline Peak glucose level in non-lethal $(\mathrm{mmol} / \mathrm{l})$ & 35 & 10 & $<0.01$ & 9 \\
\hline $\begin{array}{l}\text { Peak corticosterone level in non-lethal } \\
\text { hemorrhage }(\mathrm{nmol} / \mathrm{l})\end{array}$ & 350 & 1800 & $<0.01$ & 9 \\
\hline $\begin{array}{l}\text { Peak insulin level in non-lethal } \\
\text { hemorrhage }(\mu \mathrm{U} / \mathrm{ml})\end{array}$ & 180 & 35 & $<0.01$ & 9 \\
\hline $\begin{array}{l}\text { Survival after standardized hemorrhage } \\
\text { Involuntary stimulated skeletal muscle force }\end{array}$ & $13 / 13$ & $0 / 10$ & $<0.01$ & 11 \\
\hline $1-4$ days following hemorrhage & Higher & Lower & $<0.05$ & 14 \\
\hline $\begin{array}{l}\text { Bacterial translocation (number of rats } \\
\text { with positive cultures in mesenteric } \\
\text { lymph nodes) }\end{array}$ & $6 / 19$ & $14 / 20$ & $<0.01$ & 16 \\
\hline Survival following endoxin challenge & $60 \%$ & $20 \%$ & $<0.01$ & 13 \\
\hline
\end{tabular}

comparing rats that were either fed or fasted before stress. The rats were fasted only long enough to significantly reduce the liver glycogen reserve $(6-8 \mathrm{~h})$ or completely empty hepatic glycogen stores (24h). This brief fast resulted in marked changes in the responses to acute blood loss, as summarized in Table 1 . As is clearly shown, the differences in the responses were marked. The fasted animal responded with a substantially increased release of stress hormones (9), and an impaired fluid homeostasis (10). When the model was pushed slightly further the fasted animal succumbed to a blood loss that was not lethal in the fed rat (11). In addition, the capacity to reload glycogen to the liver after the hemorrhage differed between fed and fasted rats before the onset of the stress. Fed rats developed hyperglycemia and reloaded hepatic glycogen within hours after the bleeding had stopped. Had the rat been fasted before the hemorrhage, but infused with glucose to achieve the same level of hyperglycemia during the bleed, no glycogen was formed (12). This implied that the metabolic state per se at the onset of stress was an important factor for post stress metabolism. In separate experiments using endotoxemia as the model for stress, survival was superior in fed compared to $24 \mathrm{~h}$ fasted rats, suggesting that the phenomenon was not model-dependent (13).

Follow-up studies revealed that muscle strength was affected by $24 \mathrm{~h}$ fast before hemorrhage, and that the reduction in muscle strength was maintained for up to four days following hemorrhage (14). This suggested that functional parameters following an acute stress situation were also affected by the metabolic state before the onset of the stress. Another set of studies showed that the bacterial homeostasis in the intestines was susceptible to change already after 24 or $48 \mathrm{~h}$ of fasting (15). In addition, if the animal was subjected to blood loss, fasted rats developed a greater degree of bacterial translocation to intestinal lymph nodes compared to animals fed until the stress (16). This seemed not to be primarily due to the presence of hyperglycemia, and the subsequent circulatory improvement in the fed animals, since a glucose infusion
Table 2. Differences in a series of experiments where reactions to standardized hemorrhage were investigated in $24 \mathrm{~h}$ fasted rats treated with a $3 \mathrm{~h}$ glucose infusion prior to stress or allowed to spontaneously drink a carbohydrate-rich beverage (Carbohydrates). These groups were withheld all other nutrients for $24 \mathrm{~h}$ hours prior to stress. Control animals were also fasted for $24 \mathrm{~h}$ and received either saline infusion or free intake of water alone as placebo treatment (Placebo). Data are given as mean values, per cent or real numbers. $P$ values represent differences between groups.

\begin{tabular}{lcccc}
\hline Parameter & Carbohydrates & Placebo & p-value & Ref \\
\hline $\begin{array}{l}\text { Survival after hemorrhage } \\
\quad \text { glucose infusion) }\end{array}$ & $10 / 10$ & $0 / 10$ & $<0.01$ & 21 \\
$\begin{array}{c}\text { Survival after hemorrhage } \\
\quad \text { carbohydrate-rich beverage) }\end{array}$ & $7 / 8$ & $1 / 7$ & $<0.01$ & 22 \\
$\begin{array}{c}\text { Change in blood glucose levels } \\
\text { during hemorrhage (mmol/1) }\end{array}$ & 4.4 & -1.5 & $<0.01$ & 22 \\
$\begin{array}{c}\text { Peak insulin levels during } \\
\text { hemorrhage }(\mu \mathrm{UU} / \mathrm{ml})\end{array}$ & 80 & 22 & $<0.01$ & 22 \\
\hline
\end{tabular}

given to fasted rats during hemorrhage had no effect of bacterial translocation (17). Moreover, the same lack of effect was found when a preoperative oral intake of carbohydrates was given prior to this stress (18). Likely to contribute, however, was the peristalsis caused by ingestion of food, since intake of non-caloric bulk reduced bacterial translocation in fasted rats (19). Interestingly, these studies clearly demonstrated that only a very limited number of strains of E.coli were capable of translocation (18). Thus, if these strains were not present, no translocation occurred even in response to marked blood loss (20). The observation that these translocating strains tended to attach more strongly to the gut wall following a brief fast is also is also noteworthy, further implying a change in the interaction between host and gut bacteria as a result of a brief fast (15).

In another series of studies it was shown that treating the animals with glucose infusion (21) or intake of a small amount of a carbohydrate-rich beverage (22) completely reversed an otherwise lethal blood loss to complete recovery. It was suggested that this was mainly due to the improved capacity to develop hyperglycemia in response to hemorrhage (23), which in turn improves plasma refill $(11,24)$ and central as well as peripheral (25) circulation. In addition, pre-treatment with carbohydrates also, like chow feeding, affects the insulin release to hemorrhage (26). This further supports the hypothesis that the metabolic state before the stress impacts the responses to that stress, and that carbohydrate feeding plays a role in this. A summary of animal studies with glucose administration pre-stress is given in Table 2.

With the strong evidence showing that even a brief fast has an impact on the outcome of stress in rodents, the question whether these findings could have clinical relevance was raised. However, there were marked differences between the surgical human patient being subjected to controlled stress, and an experimental animal subjected to sub-lethal or lethal stress, albeit under controlled conditions

\section{Human studies: \\ Preoperative carbohydrates}

In order to change metabolism before the onset of surgery, it was necessary to provide some sort of feeding. The hypothesis behind these studies was that a prompt insulin response was to be provoked by feeding, and that this would change metabolism from the fasted to the fed state. This in turn would result in a less stressful response to the surgical trauma. The most convenient and well-known way 
to achieve an endogenous insulin response was by giving an intravenous glucose load. However, it was important to achieve a response in insulin release which was equivalent to that seen after a normal meal (27), about 60-70 $\mu \mathrm{U} / \mathrm{ml}$. Since the insulin response to glucose infusions is dosedependent (28), it is necessary to give a rather high infusion rate of glucose, $5 \mathrm{mg} /$ $\mathrm{kg} / \mathrm{min}$. A second goal of the preoperative treatment was to achieve loading of carbohydrates, which would then stress the issue at hand. In order to allow a large dose of glucose given overnight without causing marked diuresis from fluid overloading, a $20 \%$ glucose solution was used. This dose had previously been reported as being given in a large vein (29), without marked discomfort for the patient. Our experience of using this mode of treatment was that some patients did have some discomfort with the high-dose glucose infusion, and it seemed absolutely necessary to use only large veins and never small dorsal hand veins (unpublished observations).

Infusion of approximately $1500 \mathrm{ml} 20 \%$ glucose overnight increased hepatic glycogen by $65 \%$ compared to overnight fasting (30). Patients given this treatment entered the operation in a state of hyperinsulinemia and normoglycemia. This indicated a fed metabolic state, and that endogenous insulin release balanced the glucose infusion to maintain normoglycemia. During the operation (open cholecystectomy), there were no marked differences in the endocrine response between the treated and the untreated group. Interestingly, despite pretreatment with glucose preoperatively, glucose levels tended to remain lower during the operation compared to those found in the overnight fasted patients (30). At the same time, insulin levels were similar, indirectly indicating improved insulin sensitivity in the carbohydrate-treated patients. Using the hyperinsulinemic, euglycemic clamp technique (31), this could be confirmed by the finding of $50 \%$ reduction of postoperative insulin resistance on the day after the operation in treated compared to overnight fasted patients (32).

In another study, overnight fasted patients undergoing elective hip replacement were randomized to peroperative insulin and glucose (treatment) or saline (control) infusion. Treatment was given as a fixed insulin infusion and a variable glucose infusion to maintain normoglycemia (i.e. a hyperinsulinemic normoglycemic clamp), (33) starting a couple of hours before, throughout, and for a few hours after the operation. This allowed the determination of preoperative insulin sensitivity as well as the immediate post- operative insulin sensitivity. Control patients had their preoperative insulin sensitivity determined a week before the operation, and saline infusion given before and during the operation, and finally a determination of insulin sensitivity immediately after the operation. While the control group developed marked insulin resistance, changed their substrate utilization to fat over carbohydrates, and had a significant elevation of plasma cortisol concentrations, the opposite was found in insulin/glucose infused patients. In these patients, insulin resistance was abolished completely, substrate oxidation was maintained, and no increases in cortisol concentrations were noted (33). The development of insulin resistance was clearly a metabolic factor that seemed to have an impact on outcome. Thus, subsequent statistical analysis of postoperative insulin resistance showed that this metabolic change is an independent factor predicting the variation in length of hospital stay (LOS) following uncomplicated elective surgery (34).

When using the clamp technique for determinations of insulin sensitivity, this allows only a measure of whole body insulin sensitivity. Both the liver and peripheral tissues (mainly muscle and fat tissue) can contribute to these changes. Using stable isotopes of glucose, Nygren et al. showed that the splanchnic tissues play only a minor role, and that the main sites of postoperative insulin resistance are in the periphery (35). Further studies revealed that specific intracellular glucose transporting proteins, GLUT 4, seem to be involved in the development of postoperative insulin resistance (36). Intracellularly, glucose oxidation seems to be well maintained, while non-oxidative glucose metabolism (glycogen synthesis) is hampered $(35,36)$. Thus, in many of its main features, postoperative insulin resistance resembles type 2 diabetes mellitus. With this at hand, and knowing that postoperative patients are only rarely treated with insulin or any other diabetic drugs, this may be one explanation for the differences in recovery and well-being of patients following surgery. A lower degree of insulin resistance is therefore likely to be a better metabolic state to be in compared to a higher degree of postoperative stress-induced diabetes.

Earlier studies had shown that if large doses of intravenous glucose $(5 \mathrm{mg} / \mathrm{kg}$ body weight $/ \mathrm{min}$ ) were given before surgery, and continued after the operation, methylhistidine excretion was reduced, and a trend of improved nitrogen balance was achieved (29). To investigate whether this was due to an increase in protein synthesis in skeletal muscle, this para- meter was studied along with insulin sensitivity in patients undergoing surgery. The results of these studies showed no correlation between changes in insulin sensitivity and muscle protein synthesis (37). This is not so surprising, since insulin has not been proven to have any direct effect on muscle protein synthesis (38). The anabolic effect of insulin on protein muscle homeostasis is likely to be exerted by minimizing protein breakdown. Also, a series of studies in cardiac surgery during the 1980 s had shown that preoperative carbohydrate treatment reduced postoperative cardiac complications and reduced the damage to the cardiac muscle (39-41). One common feature in many of these studies was the preservation of glycogen stores in cardiac muscle by carbohydrate administration.

\section{Oral carbohydrates before elective surgery}

Table 3 shows data from different studies. The initial experiences using intravenous glucose treatment showed that high doses were necessary to achieve the desired insulin release and subsequent metabolic change $(28,30,32)$. This could be done, but the problem remained that this treatment, besides being inconvenient in clinical practice, caused some irritation and pain to the patients. This led to the development of an oral alternative of carbohydrate treatment.

Two criteria for preoperative oral carbohydrate treatment to be applicable in clinical practice were to be fulfilled. First of all the beverage needed to be safe. Therefore, the beverage must pass the stomach quickly. Secondly, intake of the beverage should induce an endogenous insulin response to cause the desired change of the metabolism of the patient Commercially available nutritional supplements certainly can achieve this. However, they have a slow rate of gastric emptying, making most of them potentially unsafe to use. Another alternative could potentially be sports beverages Although they contain mainly carbohydrates, the concentration of carbohydrates is too low $(<8 \%)$ to cause a response in insulin (data on file). Therefore a carbohydrate beverage was developed containing $12.5 \%$ carbohydrates, which causes an elevation in plasma insulin concentrations similar to that seen after intake of a standard meal $(27,42)$. By mixing the carbohydrates as primarily polymers (maltodextrins), the osmolality could be kept low $(<295)$, which makes gastric emptying quicker. This beverage was tested in healthy volunteers, and was shown to pass the stomach in about 90 minutes (42). Although anxiety, usually 
Table 3. Studies in patients undergoing surgery. The groups investigated were given preoperative carbohydrates either as: 1) an infusion overnight; 2) combined infusions of glucose and insulin beginning before the operation (33) or 3 ) allowed to drink a carbohydrate rich beverage, as indicated in the table. Controls were either fasted (NPO from midnight) or given saline, or a placebo beverage.

\begin{tabular}{|c|c|c|c|c|c|c|}
\hline Parameter & Carbohydrates & Controls & Carbohydrate & Controls & p-value ${ }^{b}$ & Ref \\
\hline $\begin{array}{l}\text { Cumulative S-CK activity following } \\
\text { aorto-coronary bypass } \\
\text { (area under the curve) }\end{array}$ & $\begin{array}{l}\text { Glucose } 75 \mathrm{~g} / \mathrm{l}, \text { Fructose } 75 \mathrm{~g} / \mathrm{l} \text {, } \\
\text { electrolytes }(1000 \mathrm{ml})\end{array}$ & No infusion & $188(21)$ & $284(36)$ & $<0.05$ & 39 \\
\hline $\begin{array}{l}\text { Complications after mitral valve } \\
\text { replacement }\end{array}$ & $\begin{array}{l}\text { Glucose } 20 \% \text {, } \\
45 \mathrm{mmol} \mathrm{K,} 10 \mathrm{U} \text { insulin }(1000 \mathrm{ml})\end{array}$ & No infusion & $5 / 20$ & $16 / 23$ & $<0.01$ & 40 \\
\hline $\begin{array}{l}\text { Vaspopressor dependency and ventricular } \\
\text { arrythmias following cardiac bypass surgery }\end{array}$ & $\begin{array}{l}\text { Glucose } 10-20 \% \text { with or without fat } \\
\text { in } 5 \text { separate groups of } n=54-67\end{array}$ & No infusion & $\begin{array}{l}\text { Reduced compli- } \\
\text { cations after } \\
\text { substrate loading }\end{array}$ & & $<0.02$ & 41 \\
\hline $\begin{array}{l}\text { 3-methyl histidine excretion in urine following } \\
\text { elective abdominal surgery }\end{array}$ & $\begin{array}{l}\text { Overnight glucose infusion } \\
5 \mathrm{mg} / \mathrm{kg} / \mathrm{min} \text { iv }\end{array}$ & No infusion & Lower & Higher & $<0.05$ & 29 \\
\hline $\begin{array}{l}\text { Postoperative change in insulin sensitivity (\%) } \\
\text { on 1st postoperative day following open } \\
\text { cholecystecomy }\end{array}$ & $\begin{array}{l}\text { Overnight glucose infusion } \\
5 \mathrm{mg} / \mathrm{kg} / \mathrm{min} \text { iv }\end{array}$ & NPO & $-32(4)$ & $-55(3)$ & $<0.01$ & 32 \\
\hline $\begin{array}{l}\text { Peroperative hepatic glycogen } \\
\text { (mmol/kg d.wt) }\end{array}$ & $\begin{array}{l}\text { Overnight glucose infusion } \\
5 \mathrm{mg} / \mathrm{kg} / \mathrm{min} \text { iv }\end{array}$ & NPO & 1650 & 1000 & $<0.01$ & 30 \\
\hline $\begin{array}{l}\text { Immediate postoperative change in insulin } \\
\text { sensitivity }(\%), \text { measured within hours } \\
\text { after hip replacement }\end{array}$ & $\begin{array}{l}3-4 \mathrm{~h} \text { pre op }+ \text { perop glucose } \\
\text { infusion+ fixed insulin } \\
\text { infusion }\end{array}$ & Saline infusion & +16 & -40 & $<0.01$ & 33 \\
\hline $\begin{array}{l}\text { Immediate postoperative cortisol levels } \\
\text { (and \% from preoperative) } \\
\text { Levels are nM }\end{array}$ & $\begin{array}{l}3-4 \mathrm{~h} \text { pre op + perop } \\
\text { glucose infusion } \\
+ \text { fixed insulin infusion }\end{array}$ & Saline infusion & $\begin{array}{c}180(41) \\
-32 \%\end{array}$ & $\begin{array}{l}366(83) \\
+54 \%\end{array}$ & $<0.05$ & 33 \\
\hline $\begin{array}{l}\text { Postoperative change in insulin } \\
\text { sensitivity on 1st postoperative day } \\
\text { following colorectal surgery }\end{array}$ & $\begin{array}{l}800 \mathrm{ml}+400 \mathrm{ml} \\
12.5 \% \text { CHO beverage }\end{array}$ & NPO & $-26(8)$ & $-49(6)$ & $<0.05$ & 44 \\
\hline $\begin{array}{l}\text { Immediate postoperative change } \\
\text { in insulin sensitivity }(\%) \text {, measured } \\
\text { within hours after hip replacement }\end{array}$ & $\begin{array}{l}800 \mathrm{ml}+400 \mathrm{ml} \\
12.5 \% \text { CHO beverage }\end{array}$ & $\begin{array}{l}800 \mathrm{ml}+ \\
400 \mathrm{ml} \text { placebo }\end{array}$ & $-16(7)$ & $-37(8)$ & $<0.05$ & 45 \\
\hline $\begin{array}{l}\text { Postoperative subjective discomfort } \\
\text { index } 5 \text { days after colorectal surgery } \\
\text { (mm, VAS scales, higher is worse) }^{\mathrm{c}}\end{array}$ & $\begin{array}{l}800 \mathrm{ml}+400 \mathrm{ml} \\
12.5 \% \text { CHO beverage }\end{array}$ & NPO & $22(3)$ & $38(4)$ & $<0.05$ & 46 \\
\hline
\end{tabular}

a) $800 \mathrm{ml}$ was taken during the evening before the operation and another $400 \mathrm{ml}$ 2-3 h before premedication. b) P-values represent differences between groups. c) These data are preliminarily reported only as of yet.

experienced before an operation, could potentially increase gastric passage time, the same rate was noted in patients who were about to undergo surgery (42).

These data allowed further clinical testing of the safety of this beverage. In a preliminary report on about 120 patients undergoing elective surgery after an overnight fast, intake of $400 \mathrm{ml}$ of the carbohydrate beverage or intake of placebo showed no difference in volumes (about $35 \mathrm{ml}$ ) or $\mathrm{pH}$ of gastric content at the time of anesthesia (43). These experiences have later been extended in clinical trials to involve about 300 patients, still with no adverse events recorded. In addition, we have not been able to note any adverse events in about 900 patients taking this regimen in clinical practice.

In studies of safety aspects of this treatment, patients undergoing gastroscopy have also been investigated. These patients obviously all have some problems likely to be located in the upper GI tract, and they are not routinely allowed to take any beverage prior to the investigation. However, when these patients $(3 \times 60)$ prepared for gastroscopy with an over- night fast, or the above regimens with carbohydrate or placebo beverages, again the average gastric volume was the same in all three groups. However, using $400 \mathrm{ml}$ as a dose 2 hours before the gastroscopy, two of these patients had gastric volumes of $>200 \mathrm{ml}$, and both of these had taken a beverage. This study was therefore followed by another, in which the beverage was given as $200 \mathrm{ml}$ twice, the first dose 3 hours before and the second two hours before the gastroscopy. This seemed to be a way to reduce the volumes of the outliers, since no patient had a gastric volume above $140 \mathrm{ml}(\mathrm{n}=2 \times 60$, data on file).

The metabolic effects of this treatment have also been tested. Intake of $800 \mathrm{ml}$ on the evening before the operation and another $400 \mathrm{ml}$ about 2-3 hours before the operation was shown to reduce postoperative insulin resistance as effectively as intravenous glucose infusions $(44,45)$. In addition, preliminary data suggested reduced preoperative discomfort of patients having this treatment with regard to thirst, hunger, anxiety and overall comfort (43). In another preliminary study of patients undergoing elective colorectal surgery, postoperative discomfort was significantly reduced by this preoperative preparation (46), and with a strong trend to shorter period of postoperative discomfort. A Danish group, using a very similar beverage, have reported that preoperative oral carbohydrates had a strong trend towards improving muscle strength for several weeks following colorectal surgery in a preliminary report (47). The underlying mechanisms for this somewhat surprising effect are not known.

To investigate if the change in metabolic state from the overnight fasted state to that of a carbohydrate fed state has any impact on length of stay (LOS), a couple of analyses have been performed (48). At the time of the analyses, data from three studies of this type of treatment, mentioned above, were available $(32,33,37)$. The hospital records for these studies were retrieved and LOS, and complications (none) were recorded retrospectively. All studies can be referred to as controlled trials, albeit not double-blinded. However, since the physicians taking care of the patients were not aware of which patient had received which treatment, and 
since LOS was not under study at the time of the studies, the risk of bias is very low. A multiple regression analysis was performed of the entire material (a total of 52 patients) to reveal which factors may influence the variation in LOS. These were the type of surgery, body mass index, age, and preoperative carbohydrate treatment. Using these four variables, $71 \%$ of the variation in LOS could be explained. The information on which factors influenced LOS, body mass index and age were used to determine the effect of treatment for LOS in each of the studies. In this analysis it was shown that in open cholecystectomy, LOS was reduced by 0.7 days, after hip replacement by 1.4 days and following colorectal surgery by 2.1 days. These values were the used in a metaanalysis which showed that the average effect of preoperative carbohydrate treatment was significant $(p<0.02)$ with an average reduction in LOS of 1.2 days, corresponding to approximately $20 \%$.

\section{Conclusion}

In conclusion, available data show that preoperative carbohydrate treatment for patients undergoing elective surgery has metabolic benefits postoperatively by reducing postoperative insulin resistance. This metabolic change has been shown to be an independent factor predicting the variation in length of stay. In addition, preliminary data suggest that well-being is improved pre- and postoperatively when the carbohydrates are given as a beverage 2-3 hours before the operation. This method has been tested in a total of about 1200 patients without any adverse events reported, suggesting that it is safe to use. Lastly, a meta-analysis of three prospective controlled trials indicate that LOS is reduced by about $20 \%$ by preoperative carbohydrate compared to surgery in the overnight fasted state.

\section{ACKNOWLEDGEMENTS}

This paper summarizes work, which in part has been supported by the Swedish Medical Research Council (09101), funding from the Karolinska Institutet, Sweden and from Numico Research, Holland.

\section{REFERENCES}

1. Hälso- och sjukvårdsstatistisk årsbok 1998: Socialstyrelsen ISBN 91-7201: 307-9.

2. Snow J: On chloroform and other anaesthetics. London: Churchill, 1858: 74-5.

3. Hall CC: Aspiration pneumonitis. An obstetric hazard. JAMA 1940;114:728-33.

4. Eriksson LI, Sandin R: Fasting guidelines in different countries. Acta Anaesthesiol Scand 1996:40:971-4

5. Fasting S, Søreide E, Ræder C: Changing preoperative fasting policies. Impct of a national consensus. Acta Anaesthesiol Scand 1998;42: 1188-91.

6. A Report by ASA task force on preoperative fasting. Practice guidelines for pre-operative fasting and the use of pharmacologic agents to reduce the risk of pulmonary aspiration: application to healthy patients undergoing elective procedures. Anaesthesiology 1999;90: 896-905.

7. Munro HN, Chalmers MI: Fracture metabolism at different levels of protein intake. Br J Exp Path 1945;16:396-404.

8. Järhult J: Osmolar control of the circulation in haemorrhagic hypotension. Acta Physiol Scand 1975; Suppl 423:7-84

9. Ljungqvist O, Efendic S, Eneroth P, Hamberger B, Nylander G, Ware J: Nutritional status and endocrine response to hemorrhage. Can J Physiol Pharmacol 1986;64:1185-8.

10. Ware J, Ljungqvist O, Norberg KA, Nylander $\mathrm{G}$ : Osmolar changes in haemorrhage; the effect of an altered nutritional status. Acta Chir Scand 1982;148:641-6.

11. Ljungqvist O, Jansson E, Ware J: Effects of food deprivation on survival after hemorrhage in the rat. Circ Shock 1987;22:251-60.

12. Ljungqvist O, Boija PO, Esahili $\mathrm{H}$, Larsson $\mathrm{M}$, Ware J: Food deprivation alters glycogen metabolism and endocrine response to hemorrhage. Am J Physiol 1990;22:E692-E698.

13. Esahili AH, Boija PO, Ljungqvist O, Rubio C, Ware J: Twenty-four hour food deprivation increases endotoxin lethality in the rat. Eur J Surg 1991;157:85-9.

14. Friberg B, Heilborn B, Häggmark T, Ljungqvist $\mathrm{O}$ : Food deprivation prior to stress reduces stimulated muscle force both before and after hemorrhage in the rat. Surg Res Comm 1994; 16:131-7.

15. Nettelbladt CG, Katouli M, Bark T, Möllby R, Svenberg T, Ljungqvist O: Starvation increases the number of coliform bacteria in caekum and induces bacterial adherence to caekal epithelium in rats. Eur J Surg 1996;162:135-42.

16. Bark T, Katouli M, Svenberg T, Ljungqvist O: Food deprivation increases bacterial translocation after hemorrhage in the rat. Eur J Surg 1995;161:67-71.

17. Nettelbladt CG, Katouli M, Volpe A, Bark T, Heilborn B, Muratov V, Möllby R, Svenberg T, Ljungqvist $\mathrm{O}$ : Hyperosmotic glucose infusion during haemorrhage does not reduce bacterial translocation in 24 hour fasted rats. Shock 1995;4:113-116.

18. Katouli M, Nettelbladt CG, Muratov V, Ljungqvist O, Bark T, Svenberg T: Selective translocation of coliforms adhering to cecal epithelium of rats during catabolic stress. J Med Microbiol 1997;46:571-8.

19. Nettelbladt CG, Katouli M, Heilborn B, Möllby $\mathrm{R}$, Svenberg T, Ljungqvist O: Bulking fibre prevents translocation of an efficiently translocating Escherichia coli strain in rats. Clin Nutr 1998; 17:185-90.

20. Nettelbladt CG, Katouli M, Bark T, Svenberg T, Möllby R, Ljungqvist O: Orally inoculated Escherichia coli strains colonize the gut and increases bacterial translocation after stress in rats. Shock. In press.

21. Alibegovic A, Ljungqvist O: Pretreatment with glucose infusion prevents fatal outcome after hemorrhage in food deprived rats. Circ Shock 1993;39:1-6.

22. Nettelbladt CG, Alibegovic A, Ljungqvist $\mathrm{O}$ : Pre-stress carbohydrate solution prevents fatal outcome after hemorrhage in $24 \mathrm{~h}$ food deprived rats. Nutrition 1996;12:696-9.

23. Ljungqvist $\mathrm{O}$, Alibegovic A: Hyperglycemia and survival after hemorrhage. Eur J Surg 1994; 160:465-66.

24. Ljungqvist $\mathrm{O}$, Boija PO, Ware J: The effect of hyperosmolar infusions on survival after hemorrhage. Acta Chir Scand 1989;155:433-9.

25. Quiros G, Ware J: Cardiovascular and metabolic alterations caused by haemorrhage in fed and starved rats. Acta Physiol Scand 1983; 117:397-403.

26. Ljungqvist $\mathrm{O}$, Alibegovic A, Heilborn B: Modulating the insulin response to hemorrhage in the starved rat with pre-stress glucose infusion. Surg Res Comm 1998;19:85-96.

27. Gutniak M, Grill V, Efendic S: Effect of composition of mixed meals - low versus high carbohydrate content - on insulin, glucagon, and somatostatin release in healthy humans and in patients with NIDDM. Diabetes Care 1986;9:
244-9.

28. Wolfe RR, Allsop JR, Burke JF: Glucose metabolism in man: responses to intravenous glucose infusion. Metabolism 1979·28:210-20.

29. Crowe PJ, Dennison A, Royle GT: The effect of preoperative glucose loading on postoperative nitrogen metabolism. Br J Surg 1984;71:635-7.

30. Thorell A, Alston-Smith J, Ljungqvist O: The effect of preoperative carbohydrate loading on hormonal changes, hepatic glycogen and glcoregulatory enzymes during abdominal surgery. Nutrition 1996;12 (10):696-9.

31. DeFronzo RA, Tobin JD, Andres R: Glucose clamp technique: a method for quantifying insulin secretion and resistance. Am J Phsyio 1979;273:E214-E223.

32. Ljungqvist $\mathrm{O}$, Thorell A, Gutniak M, Häggmark T, Efendic S: Glucose infusion instead of preoperative fasting reduces postoperative insulin resistance. J Am Coll Surg 1994 178:329-36.

33. Nygren J, Thorell A, Soop M, Efendic S, Brismar K, Karpe F, Nair KS, Ljungqvist O Perioperative insulin and glucose infusion maintains normal insulin sensitivity after surgery. Am J Physiol 1998;275:E140-E148.

34. Thorell A, Nygren J, Ljungqvist O: Insulin resistance - a marker of surgical stress. Curr Op Clin Nutr Metab Care 1999;2:69-79.

35. Nygren J, Thorell A, Efendic S, Nair KS Ljungqvist $\mathrm{O}$ : Site of insulin resistance after surgery: the contribution of hypocaloric nutrition and bed rest. Clinical Science 1997;46:571-8

36. Thorell A, Nygren J, Hirshman MF, Hayashi T, Nair KS, Horton ES, Goodyear LJ, Ljungqvist $\mathrm{O}$ : Surgery-induced insulin resistance in human patients: relation to glucose utilization and transport. Am J Physiol 1999;276:E754-E761.

37. Thorell A, Essén P, Ljungqvist O, McNurlan MA, Calder AJ, Garlick PJ, Wernerman J: Postoperative insulin resistance and muscle protein synthesis rate. Clin Nutr 1992;11:P48.

38. McNurlan MA, Essén P, Thorell A, Calder AG, Anderson SE, Ljungqvist O: Response of protein synthesis in human skeletal muscle to insulin: an investigation with $\mathrm{L}-\left({ }^{2} \mathrm{H}_{5}\right)$ phenyl alanine. Am J Physiol 1994;267:E102-E108.

39. Berggren H, Ekroth R, Hjalmarson $\AA$, Nilsson F, Schlossman D, Waldenström A, Waldenström J, William-Olsson G: Enhanced myocardial protection from preoperative carbohydrate infusion in addition to maintained betablockade. J Cardiovasc Surg 1985;26:454-6.

40. Oldfield GS, Commerford PJ, Opie LH: Effects of preoperative glucose-insulin-potassium on myocardial glycogen levels and on complications of mitral valve replacement. J Thorac Cardiovasc Surg 1986;91:874-8.

41. Lolley DM, Myers WO, Jefferson FR, Sautter RD, Tewksbury DA: Clinical experience with preoperative myocardial nutrition management. J Cardiovasc Surg 1985;26:236-43.

42. Nygren J, Thorell A, Jacosson H, Schnell PO, Ljungqvist $\mathrm{O}$ : Preoperative gastric emtying; the effects of anxiety and carbohydrate administration. Ann Surg 1995;222:728-34

43. Nygren J, Thorell A, Lagercranser M, Almström C, Hammarqvist F, Ljungqvist O: Safety and patient well-being after preoperative oral intake of carbohydrate rich beverage. Clin Nutr 1996;suppl 1:P28.

44. Nygren J, Soop M, Thorell A, Efendic S, Nair KS, Ljungqvist O: Preoperative oral carbohydrate administration reduces postoperative insulin resistance. Clin Nutr 1998;17:65-71.

45. Nygren J, Soop Thorell A, Ljungqvist O: Preoperative oral carbohydrates and postoperative insulin resistance. Clin Nutr 1999; 18:259-64.

46. Hausel J, Nygren J, Almström C, Thorell A, Ljungqvist O: Preoperative oral carbohydrates improve well being after elective colorectal surgery. Clin Nutr 1999;18 (Suppl 1):80.

47. Henriksen MG, Hansen HV, Dela F, Haraldsted V, Rodt SA, Hessov I: Preoperative feeding might improve postoperative voluntary muscle function. Clin Nutr 1999;18 (Suppl 1):82

48. Ljungqvist $\mathrm{O}$, Nygren J, Thorell A: Preoperative carbohydrates instead of preoperative fasting reduces hospital stay following elective surgery. Clin Nutr 1998;17 (suppl.1) O 10. 